\title{
Study on Tower Models for EHV Transmission Line
}

\author{
Bao-Qing Xu ${ }^{1}$, Xiao-FeiZhang ${ }^{1}$, Sen $L v^{1}$, Rui-Xin Ding ${ }^{1}$ and Lu Wang ${ }^{2}$ \\ ${ }^{1}$ Sanmenxia Power Supply Company, State Grid Henan Electric Power Company, Sanmenxia, China \\ ${ }^{2}$ North China Electric Power University, Baoding, China
}

\begin{abstract}
Lightning outage accident is one of the main factors that threat seriously the safe and reliable operation of power system. So it is very important to establish reasonable transmission tower model and evaluate the impulse response characteristic of lightning wave traveling on the transmission tower properly for determining reliable lightning protection performance. With the help of Electromagnetic Transient Program (EMTP), six 500kV tower models are built. Aiming at one line to one transformer operating mode of $500 \mathrm{kV}$ substation, the intruding wave overvoltage under different tower models is calculated. The effect of tower model on intruding overvoltage has been studied. The results show that different tower models can result in great differences to the calculation results. Hence, reasonable selection of the tower model in the calculation of back- strike intruding wave is very important.
\end{abstract}

\section{Introduction}

$500 \mathrm{kV}$ substation is the pivot of power system, and its performance is very important to power system. Lightning stroke in substation may lead to a lot of damage to electrical equipment. Hence, it is very important to calculate the over voltage of tower struck by lightning.

Tower model is important to considering lead-in line of the establishment of lightning invasion wave over voltage model. The lightning tower model was carried out by lots of researches [1-4]. But reflection on the process of the tower surge is still controversial, the fundamental reason is that the physical process of tower internal wave propagation is not clear. Especially with large span high tower widely used, lightning stoke opportunity, equivalent inductance of tower, overhead potential of tower and induced overvoltage are higher than common tower. At present, in the transmission line lightning protection analysis, three models, namely lumped inductance model, single-surge impedance model and multi-surge impedance model are selected for the tower simulation.

A $500 \mathrm{kV}$ substation is selected to calculate over voltage by using electromagnetic transient program (EMTP), combining substation incoming lines with thundering protection of transmission line and double circuit lines on same tower. The calculation method of tower surge impedance is introduced and six models, such as lumped inductance model, single-surge impedance model, lossy multi-surge impedance model and its simplified model, multi wave nondestructive model and Xi'an Jiao Tong university model are presented in paper. The effects of different models of substation lightning invasion wave are analyzed. Results show that different tower models can result in great differences to the calculation results. Hence, reasonable selection of the tower model in the calculation of backstrike intruding wave is very important.

\section{Tower model}

If the tower resistance can be ignored and the low precision is permitted, tower can be equivalent to one inductance, shown in figure 1(a), called lumped inductance model [5]. Formula of lumped inductance model is that:

$$
L_{g t}=\tau Z_{g t}=\frac{h}{c} Z_{g t}
$$

The surge impedance model is considered as a kind of transient wave process cross the tower. In the surge impedance models, tower over voltage is the results of superposition of the lightning over voltage and the reflected voltage wave from the tower bottom. The calculation principle of the single-surge impedance of tower is most regarded the tower as cone. Tour tower models provided by IEEE [6] are shown in figure.1 (b).

In figure.1 (b), shape1, shape 2 and shape 3 are the models used for general towers. The surge impedance of them is calculated by (2)-(4).

$$
\begin{gathered}
Z_{\text {shape } 1}=60 \ln \frac{\sqrt{2\left(H^{2}+r_{3}{ }^{2}\right)}}{r_{3}} \\
Z_{\text {shape } 2}=60 \ln \frac{2 \sqrt{2} H}{r_{2}}-60
\end{gathered}
$$




$$
Z_{\text {shape } 3}=\sqrt{\frac{\pi}{4}} \cdot 60\left[\ln \cot \left(\frac{1}{2} \tan ^{-1} \frac{r_{\text {avg }}}{h_{1}+h_{2}}\right)-\ln \sqrt{2}\right]
$$

where, $r_{\text {avg }}=\frac{r_{1} h_{2}+r_{2}\left(h_{1}+h_{2}\right)+r_{3} h_{1}}{h_{1}+h_{2}}$

The shape 4 is the surge impedance model of tower and calculated by formula (5)

$$
Z_{\text {shape } 4}=\frac{Z_{1} Z_{2}}{Z_{1}+Z_{2}}
$$

In the formula (5), $Z 1$ is surge impedance of a vertical cylinder, Z2 is the weighted average of surge impedance of horizontal cylinder and vertical cylinder. Z1 and Z2 are calculated from (6) and (7).

$$
Z_{1}=60 \ln \frac{2 \sqrt{2} H}{r}-60
$$

The shape 4 is the surge impedance model of tower and calculated by formula (5)

$$
Z_{2}=\left(D \cdot 60 \ln \frac{2 H}{r}+H Z_{1}\right) /(H+D)
$$

Lossy multi-surge impedance model is established based on the experiment. $1 / 70 \mu$ s oblique wave current is injected into the top of the tower in the experiment, and the tower model and the calculation formula are obtained from the measurement results. The model consists of several lossless lines and several parallel connection of damping resistor $\mathrm{R}$ and damping inductance $\mathrm{L}$, as shown in figure 1(c). The attenuation of shock wave is realized by resistance in the model, and the characteristic of high frequency attenuation is achieved by parallel connection of inductance and resistance [7-8]. For the $500 \mathrm{kV}$ tower, surge impedance is achieved by experiment that $\mathrm{Zt} 1=\mathrm{Zt} 2=\mathrm{Zt} 3=\mathrm{ZT} 1=220 \Omega, \quad \mathrm{Zt} 4=\mathrm{ZT} 2=150 \Omega . \quad$ Damping resistor $\mathrm{R}$ and damping inductance $\mathrm{L}$ are calculated by (8)-(10), where vt denotes the propagation velocity of shock wave in the tower, and vt is 0.85 times than the speed of light.

$$
\begin{gathered}
R_{i}=\frac{-2 Z_{T 1} \ln \sqrt{\gamma_{1}}}{h_{1}+h_{2}+h_{3}} \cdot h_{i} \quad(i=1,2,3) \\
R_{4}=-2 Z_{T 2} \ln \gamma_{2} \\
L_{\mathrm{i}}=\alpha \cdot \tau \cdot R_{i}=\alpha \cdot\left(\frac{2 H}{v_{t}}\right) \cdot R_{i} \quad(i=1,2,3,4)
\end{gathered}
$$

Takamitsu proposed simplified model based on lossy multi-surge impedance model, as shown in figure 1(d) [9]. Parameters of the model are the same with $\mathrm{Zt} 1$ and $\mathrm{Zt} 2$ in lossy multi-surge impedance model.

T.Hara proposed equivalent tower to lossless multisurge impedance. The model will be subdivided into tower main materials d diagonal materials a and tower cross-arm, simulating with lossless circuit respectively, as shown in figure 1(e) [10-12]. The formula of main materials surge impedance is got by (11).

$$
Z_{T K}=60 \ln \left(\frac{2 \sqrt{2} h_{k}}{r_{e k}}-2\right),(k=1,2,3,4)
$$

where,

$$
r_{e k}=\left\{\begin{array}{cc}
\sqrt[8]{2} \cdot\left[\sqrt[3]{r_{T K} \cdot\left(r_{B}{ }^{\prime}\right)^{2}}\right]^{1 / 4} \cdot\left[\sqrt[3]{R_{T K} \cdot\left(R_{B}{ }^{\prime}\right)^{2}}\right]^{3 / 4} & (k=1,2,3) \\
\sqrt[8]{2} \cdot\left[\sqrt[3]{r_{T K} \cdot\left(r_{B}\right)^{2}}\right]^{1 / 4} \cdot\left[\sqrt[3]{R_{T K} \cdot\left(R_{B}\right)^{2}}\right]^{3 / 4} & (k=4)
\end{array}\right.
$$

The tower diagonal materials surge impedance is calculated by (13), and the length is assumed 1.5 times than the corresponding main material.

$$
Z_{L K}=9 Z_{T K}(k=1,2,3,4)
$$

The tower cross-arm can be treated as a normal horizontal conductor to calculate the surge impedance.

$$
Z_{A K}=60 \ln \left(\frac{2 h_{k}}{r_{A k}}\right) \quad(k=1,2,3,4)
$$

Xi'an Jiao Tong University model is another multisurge impedance model with the concept that surge impedance is different at different height based on vertical conductor. Same as lossy multi-surge impedance model, this model is divided into main support and ordinary support, and each part is assumed to be uniformly distributed. The surge impedance of each part is calculated by the calculation of tower geometrical dimension, as shown in figure 1(f) [13]. The formula of this model is same with ZTK and ZLK in lossless multisurge impedance model.

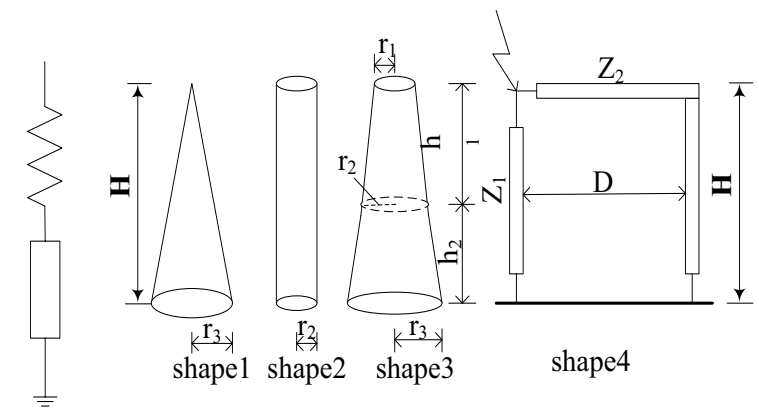

(a)

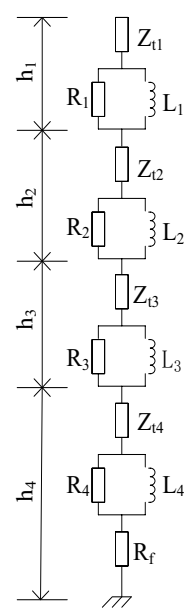

(c) (b)

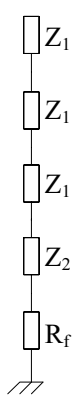

(d)

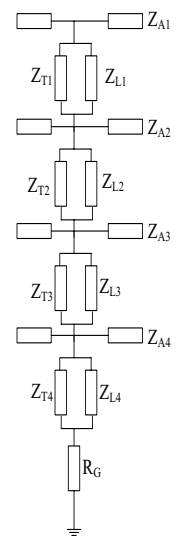

(e)

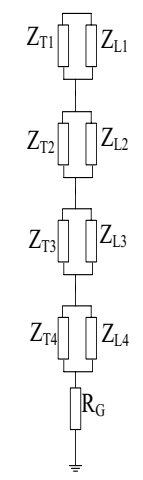

(f)
Figure 1. Six tower models: (a)lumped inductance model (b)IEEE tower model

(c)lossy multi-surge impedance model

(d)simplified model

(e)lossless multi-surgeb Impedance

(f)Xi'an Jiao Tong University model. 


\subsection{Computational Condition}

In this paper, one line to one transformer mode of $500 \mathrm{kV}$ was selected. Figure 2 is the equivalent circuit diagram. Overvoltage in six tower models was calculated respectively.

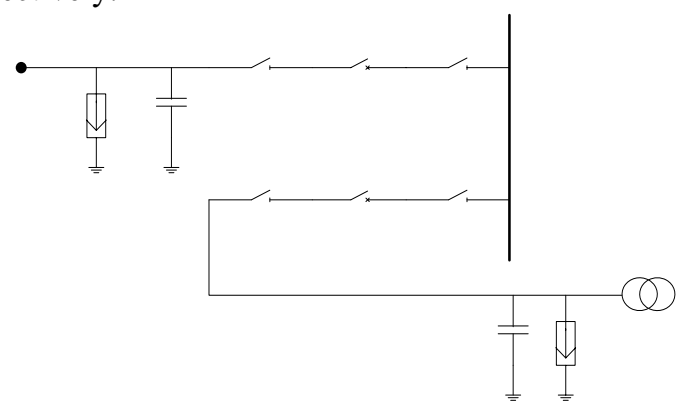

Figure 2. Equivalent circuit diagram of Substation.

The lightning current is selected as $2.6 / 50^{\mu s}$, the amplitude is $216 \mathrm{kA}$, and the lightning channel surge impedance is $300 \Omega$. \#2 is chosen to the lightning point, which located the range of $2 \mathrm{~km}$ in substation incoming lines. Conductor type is $4 \times$ LGJ-400/50, lightning shield line type is LBGJ-120-40AC.

Arrester is installed at the entrance of the substation and beside the main transformer. The volt-ampere characteristics of arrester are shown in table 1.

Table 1. Arrester volt-ampere characteristics.

\begin{tabular}{|c|c|c|c|c|c|c|c|}
\hline \multirow{2}{*}{$\begin{array}{c}\text { Arreste } \\
\mathbf{r}\end{array}$} & $\begin{array}{c}\text { rated } \\
\text { voltag } \\
\mathbf{e}\end{array}$ & \multicolumn{6}{|c|}{ volt-ampere characteristics } \\
\cline { 3 - 8 } & $\mathbf{( k V )}$ & $\mathrm{I}(\mathrm{kA})$ & 1 & 3 & 5 & 10 & 20 \\
\hline $\begin{array}{c}\text { Line } \\
\text { type }\end{array}$ & 444 & $\begin{array}{c}\mathrm{V}(\mathrm{kV} \\
)\end{array}$ & $\begin{array}{c}92 \\
6\end{array}$ & $\begin{array}{c}96 \\
8\end{array}$ & $\begin{array}{c}98 \\
8\end{array}$ & 1030 & 1106 \\
\hline $\begin{array}{c}\text { station } \\
\text { type }\end{array}$ & 420 & $\begin{array}{c}\mathrm{V}(\mathrm{kV} \\
)\end{array}$ & $\begin{array}{c}87 \\
6\end{array}$ & $\begin{array}{c}91 \\
6\end{array}$ & $\begin{array}{c}93 \\
4\end{array}$ & 974 & 1052 \\
\hline
\end{tabular}

The lumped inductance is calculated by (1) that inductance value is $33.35 \mu \mathrm{H}$. The single surge impedance is calculated to $106.4 \Omega$ by (4). Lossess multi-surge impedance model calculation results are shown in table 2 .

Table 2. Calculation results of multi surge impedance.

\begin{tabular}{|c|c|c|c|c|}
\hline $\mathbf{K}$ & $\mathbf{1}$ & $\mathbf{2}$ & $\mathbf{3}$ & $\mathbf{4}$ \\
\hline $\operatorname{Zi}(\Omega)$ & 220 & 220 & 220 & 150 \\
\hline $\operatorname{Ri}(\Omega)$ & 4.589 & 9.906 & 10.051 & 16.736 \\
\hline $\operatorname{Li}(\mathrm{uH})$ & 2.401 & 5.182 & 5.258 & 8.755 \\
\hline
\end{tabular}

$\mathrm{Zi}$ in lossess multi-surge impedance model simplified model is same with table2. The calculation results of lossless multi-surge impedance model are shown in figure 3. The calculation results of Xi'an Jiao Tong University model are same with ZTK and ZLK in figure 3 . The tower span is $500 \mathrm{~m}$, and the grounding resistance is $15 \Omega$.

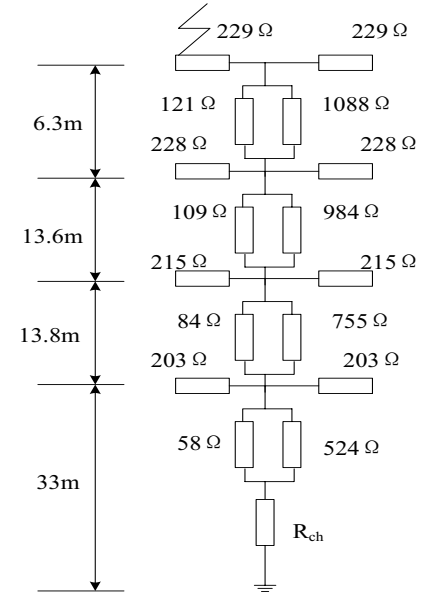

Figure 3. Lossless multi-surge impedance model.

All electrical facilities in the substation are simulated with the entrance capacitance. Capacitance values are shown in table 3 .

Table 3. Electrical equipment inlet capacity.

\begin{tabular}{|c|c|c|}
\hline Device Name & Symbol & $\begin{array}{c}\text { Capacitance Value } \\
(\mathbf{p F})\end{array}$ \\
\hline Circuit breaker & $\mathrm{D}$ & $\begin{array}{c}330 / 150(\text { Closing / } \\
\text { Division) }\end{array}$ \\
\hline Isolating switch & $\mathrm{G}$ & $\begin{array}{c}80 / 40(\text { Closing / } \\
\text { Division })\end{array}$ \\
\hline $\begin{array}{c}\text { Current transformer } \\
\text { capacitor voltage } \\
\text { transformer }\end{array}$ & $\mathrm{CT}$ & 700 \\
\hline CVT & 5000 \\
\hline transformer & $\mathrm{B}$ & 5000 \\
\hline
\end{tabular}

\subsection{Computational Results}

Six models are used to simulate the tower respectively, under one line to one transformer operation mode. Results of lightning intruding overvoltage in substation are shown in table 4.

Overvoltage is highest when using lossy multi-surge impedance model, the second is the simplified model, and then is lumped inductance model, single surge impedance model, Xi'an Jiao Tong University model, lossess multisurge impedance model. Due to the resistance and inductance calculation formulas of lossy multi-surge impedance model are obtained by experiment using $1 / 70^{\mu S}$ oblique current wave, calculation results exist error. Overvoltage are different in capacitor voltage transformer with six models, lightning wave can enter secondary equipment through the capacitor voltage transformer in substation, so correction of tower model simulation have great influence to prevent substation lightning intruding overvoltage.

Arresters appear overvoltage first, followed by CVT and $\mathrm{B}$, showing delay of wave process, as shown in figure 4. In arrester, overvoltage of lossy multi-surge impedance model is higer than lossess multi-surge impedance model, but the attenuation is faster, as shown in figure 5, 
showing characteristics of inductance and resistance branch.

Table 4. Lightning over voltage of substation equipment under six lightning tower models.

\begin{tabular}{|c|c|c|c|}
\hline & Arrester(kV) & $\mathbf{C V T ( k V )}$ & $\mathbf{B ( k V )}$ \\
\hline $\begin{array}{c}\text { lumped inductance } \\
\text { model }\end{array}$ & 1123.1 & 1073.7 & 1119.7 \\
\hline $\begin{array}{c}\text { single-surge } \\
\text { impedance model }\end{array}$ & 1060.5 & 1058.1 & 1104.6 \\
\hline $\begin{array}{c}\text { lossy multi-surge } \\
\text { impedance model }\end{array}$ & 1099.6 & 1109.5 & 1253.3 \\
\hline simplified model & 1095.7 & 1107.0 & 1250.8 \\
\hline $\begin{array}{c}\text { lossess multi-surge } \\
\text { impedance model }\end{array}$ & 1022.6 & 1028.2 & 1095.8 \\
\hline $\begin{array}{c}\text { Xi'an Jiao Tong } \\
\text { university model }\end{array}$ & 1056.7 & 1030.9 & 1090.4 \\
\hline
\end{tabular}

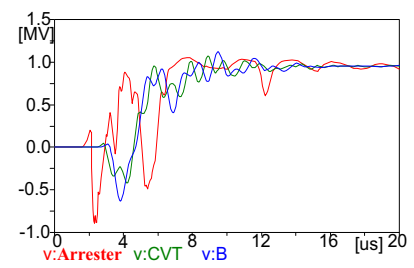

(a)

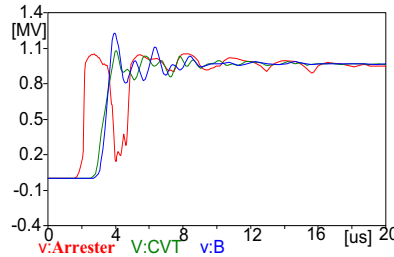

(c)

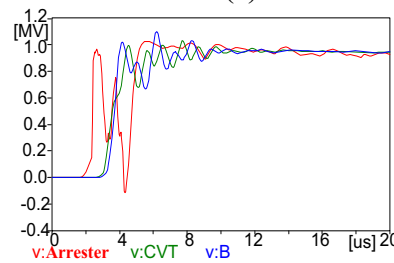

(e)

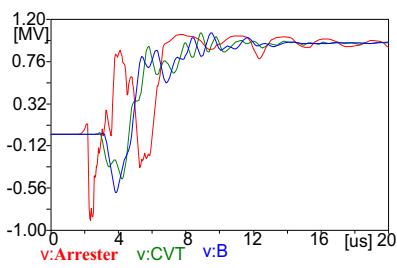

(b)

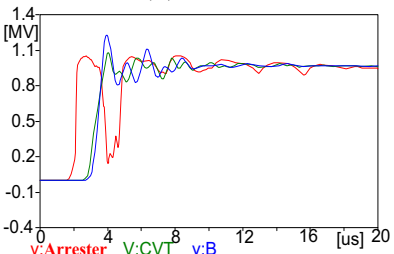

(d)

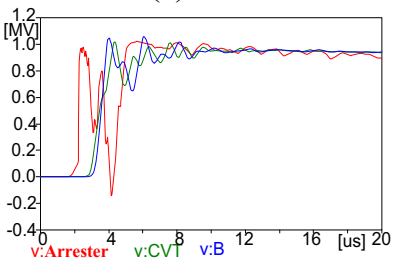

(f)
Figure 4. Calculation result of six models:(a)lumped inductance model

(b)single-surge impedance model

(c)lossy multi-surge impedance model

(d)simplified model

(e)lossess multi-surge impedance model

(f)Xi'an Jiao Tong university model.

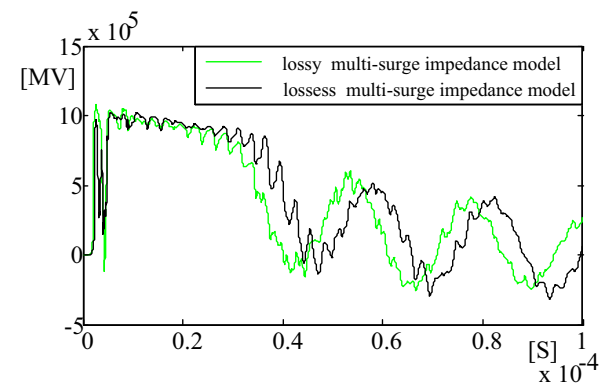

Figure 5. Arrester overvoltage of two models.

\section{Conclusion}

(1)Lumped inductance model is treated the tower as an equivalent inductance, and the potential of any point on the tower is same. Relative to the surge impedance model, lumped inductance model does not reflect lightning current propagation process cross the tower and the influence of reflection wave to each tower node potential when the lightning strikes the tower, that is the difference with the actual tower model.

(2)The wave propagation process of lightning current is considered in single surge impedance model, but the model does not take into account the structure of the tower itself, and the influence of the tower cross-arm, pillar and insulator flashover process are ignored.

(3)A hierarchical simulation of the tower is shown in lossy multi-surge impedance model, according to the actual height and cross-arm position on the tower. The parallel branch of the $\mathrm{R}$ and $\mathrm{L}$ reflects the attenuation process of the traveling wave transmission in the tower. But in the simulation results of the model, substation equipment overvoltage is the highest. One reason is the calculation formula of the model parameters directly using foreign calculation formula of damping resistance and damping inductance, obtained from experiment. This calculation is bound to lead to a certain error; on the other hand, lightning current also have an impact on the results. Due to the use of the lightning current waveform is domestic commonly used 2.6/50us double exponential waveform, which wave head is 2.6 time than the head wave of $1 / 70 \mu$ s oblique wave current. The simplified model is obtained from lossy multi-surge impedance model, and the simulation results are close, so the 2.6/50us lightning current will have a same impact on lossy multi-surge impedance simplified model. Therefore, it's necessary to test lossy multi-surge impedance model of tower aiming at the domestic commonly using 2.6/50us double exponential lightning wave.

(4) Results of lossess multi-surge impedance model are close to Xi'an Jiao tong University model, both the two models segmenting the tower according to the concept that surge impedance are different at the different height of vertical conductor of the tower. But the results of overvoltage of the model of Xi'an Jiao Tong University are higher than the lossess multi-surge impedance model. The reason is the tower cross-arm model is not considered in Xi'an Jiao Tong University model, and propagation time of electromagnetic wave on the tower cross-arm is ignored. Therefore, the overall structure of the tower can be reflected in lossess multisurge impedance model, and is often applied in the actual transmission line tower modeling. More tower section number, in calculation, the model is more precise, but the corresponding modeling will be more complex, so selecting the number of segment need to consider the accuracy and complexity of the modeling integrally.

(5)Lossy multi-surge impedance model and lossess multi-surge impedance model are both considered the height of tower and the position of tower cross-arm. Considering the attenuation of traveling wave in the transmission process of tower is the advantages of lossy multi-surge impedance model, but the consideration of 
the tower cross-arm surge impedance is the advantages of lossess multi-surge impedance model, so the two models can be combined in later simulation.

\section{References}

1. A. Ametani, Y. Kasai, J. Sawada, IEE Proc-Gener Transm Distrib 141, 339 (1955)

2. B. Yoshihiro, IEEE Transactions on Power Delivery 14, 630 (1999)

3. B. Yoshihiro, I. Masaru, IEEE Transactions on Power Delivery 15, 1010 (2000)

4. Zhang Y.-J., W.-X. Si-Ma, Z.-J. Zhang, High Voltage Engineering 32, 93 (2006)

5. Y. Xu, Y.-Z. An, Shaanxi Electric Power 3, 37 (2011)

6. DL/T620-1997. Overvoltage Protection and Insulation Coordination for AC Electrical Installations, (1997)

7. D.-J. Wang, H. Zhou, J.-M. Chen, Power System Technology 31, 11(2007)

8. W.-H. Wu, X.-L. Cao, China Water Resources and Hydropower Publishing House, (2012)

9. Z.-X. Yuan, H. Li, L. Xiang, High Voltage Engineering 34, 867 (2008)

10. Takamitsu Ito, Toshiaki Ueda, IEEE Transactions on Power Delivery 18, 545 (2003)

11. Y. Zhang, Y.-D. Gao, B. Du, W. Shi, JOURNALOF XI'AN JIAOTONG UNIVERSITY 38, 365 (2004)

12. W.-W. Huang, M.-J. Xiao, X. Yang, High Voltage Apparatus 51, 166 ( 2015)

13. X.-H. Zhang, Electrical and Electronic Engineering (2014) 